$\gamma$

\title{
Optical Diagnostic in the Advanced Test Accelerator (ATA) Environment
}

Y. P. Chong, J. P. Cornish and D. Donnelly

Prepared for SPIE's 1987

Technical Symposium

Southeast

Orlando, FL

17-22 May, 1987

\section{Beam}

\section{Research Program}

Lawrence Livermore National Laboratory 
This documeat was preptred as an account of work sponsored jointly by the U.S. Departaneat of Enerzy and the Defense Adranced Reserch Projects A gency. Neither the United State Gorennest nor the Unjrersity of Califorala nor any

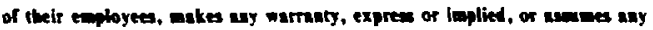

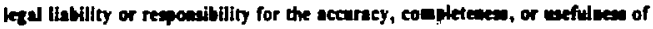
any information, apparates, produce, or proces dieclosed, or represeots that its we would wot blriage prtrately owned rights. Reference bereln to eay specific conmereid products, process, or service by trale mane, tradenari, menfic-

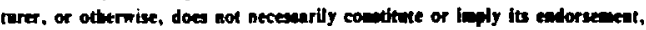
recomentation, of faroriog by the United Steves Gererement or the Undrez-

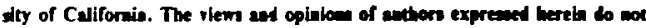
necessurily state or reflect those of the United States Government thereot, aw

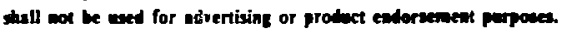




\section{DE87 010338}

Optical diagnostics in the advanced test accelerator (ATA) environment"

Y. P. Chong. J. P. Cornish, and D. Donnelly

Lawrence Livermore Hational Laboratory

University of Californta

Livermore, CA 94550

\section{Abstract}

The ATA is a 50-MeV, 10-kA, 70-ns pulsed electron bean accelerator that generates an extremely harsh environment for diagnostic measurenents. Diagnostlc targets placed in the beamline are subfect to damage, frequently being destroyed by a single pulse. High radiation ( $x$-ray, gamma, and neutrori) and

electromagnetic interference levels preclude placing components near the beamilne that are susceptible to radiation damage. Examples of such components are integrated circuit elements, hydrocarbons such as Teflon insulation, and optical components that darken, resulting in eransmission loss. 0ptical diagnostics play an important part in measuring experimental parameters such as the beam current density profile. A large number of optical lines of sight (LOS) are routinely deployed along the experimental beamlines that use the ATA beam. Gated TV caneras are located outside the accelerator tunnel, because the tunnel is inaccessible during operations. We w1ll describe and discuss the difficulties. problems, and solutions encountered in making optical measurements in the ATŔ environment.

\section{Introduction}

The AlA is a linear induction accelerator that produces $350-\% e V, 10-k A$. 70-ns electron beam. It is typicalty pulsed at $1 \mathrm{~Hz}$. High radiation levels of gamm rays, $x$-rays, and neutrons are generated during each pulse. Radiation danage restricts severely the type of materlals and componencs that may be placed near or in the beanline. Examples are integrated circuit eienents that are destroyed by the electronagnetic pulse, hydrocarbons such as Teflon insulation that eventualiy turn into powder, and optical windows that suffer radiation darkening. For simplicity, we rhose to place all radiation-susceptible camponents outside the tunnel shield except for ccmponents where it was unavoldable such as vacuum-air interface windows. The added advantage was that personnel access to hardware was conventent and in a safe radiation region.

A primary diagnostic involves optical measurement of the electron bean parameters. A brief description of the optical diagnostic is given, followed by measurements of fluorescence induced in a fiber-optic bundle and radiation darkening of a beamline window component.

\section{Optical dtagnostics system}

The optical diagnostics system ${ }^{2}$ is shown in component form in Fig. I. Optical emission is generated by the electron beam incident on a target foil inserted into the beam path in vacuum. In a gas-filled region the electron beam Induces optical emisslons through atomic and molecular excitations. An optical line-of-sight (LOS) system relays the image to the detector. which is located outside the hostile radiation environment. The detector may comprise a gated image-intensifier optically coupled to a CCD TV camera that records a 2-0 spatial inage. Time resolution of 5 ns is attainable. The detector can be a microchannel-plate photoneter that allows nanosecond time resolution of the spatially-fntegrated optical signal. For a 1-D spatial image with picosecond time resolution a streak camera ts used. The digitized image or trace signal is fed tnto a computer for image processing and data reduction.

Figure 2 shows the logic circuit and timing scheme when the gated intensifier CCD TV camera is deployed. Figure 3 shows an optical system for a dual LOS arrangenent with dual detectors. Note the lead housings that shield the outside region from radiation leaking through the sleeve in the tunnel. Nany of these optical diagnostic systems (typically with just a single detector) are deployed along the aTA beamline at locations where measurenent of the electron beam current denstty profile is desired. Examples of the foil and gas optical enissions are shown in figs. 4 and 5 respectively. Further discussions of data utilization are presented in a companion paper. 3

\section{Fiber-optic radiation test}

A coherent fiber-optic bundle (0ainichi-Hippon 6000 pixel, pure fused stlica) was tested for fluorescence and transient darkening in the ATA radiation environment. Figure 6 shows the experinental configuration. The light pulse from a xenon flashlamp was sent through optical filters mounted on a renote-controlled ratatable whee1. The flber-optic bundle gulded the pulse to a microchannel-plate phototube that was shielded against radiation in a lead housing. The fiber-optic cable was laid transversely over the ATA beamline to subject it to radiation. The radiation dosage was measured by placing

*Performed jolntly under the auspices of the U.S. DOE by LLML Under W-7405-ENG-48 and for the DOD under OARPA, ARPA order No. 4395 , monitored by NSHC.

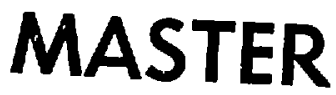


a terainated cable over the beanline and recording the radiation-1nduced signa\}. The signal is caused by compton and pair prodistion electrons produced by radiation incident on the coaxial cable. Struve 4 has mesured the induced 5 ignal for varlous cable types and dose rate. Knowing the caltbration factor, the radiation dosage was obtained.

In a preliminary test, the xenon flashlamp was found to be too low in its light output cohpared to the transtent fluorescence induced in the fiber by the electron bean. The fluorescent peak signal was three ties higher than the flashlang peak signal at the same phototube voltage setting. Further tests on radiation darkening of the fiber are dependent on finding a brighter light source.

\section{Radiation-induced fluorescence}

The fluoresience induced in the fiber cable was measured with the flashlamp turned off. Each fluorescent signal detected by the phototube was recorded as a function of $t$ ime on a Tektronix 7912 transient digitizer. The integrated signal is plotted versus shot number in Fig. 7 . Initially the electron beam was tuned for minianum radiation spill. For the later shots the beam was tuned to dump more current in the region of the fiber to increase the radiation level.

The fluorescent signal is plotted as a function of radiztion dose in $\mathrm{Fig}$. B. The signal is seen to increase alnost lineariy with the radiation dose rate up to a noximum of about 2500 rads/pulse, beyond which it decreases. The peak indicates the radiation level beyond which the fiber suffers darkening and. therefore, a large transisisston loss.

Figure 9 shows the fluorescent signal nomalized to the dose rate, plotted vs toisl dose rate. Disregarding the two dips for the monent, the data shows an almost flat portion followed by a steep decline until it flattens out at the botton. We offer the following explanation: The flat part indicates no permanent darkening has occurred out to the shoulder. Beyond the shoulder permanent darkening sets in until the flat botton is reached where no additional darkening is possible. The dips are probably due to recovery from cransient darkening effects. Since the shots were not taken on a constant time interval. the dips indicate the shots that were taken too sobn one after another. There was insufficient time to recover fully fron transient darkening.

\section{Rediation darkening of optical windou}

Each LOS views the bean through an optical window that is located about a foot from beanline axis. Ordinary or low-grade quartz suffers more than $50 x$ transnission loss after $1-2$ h runtine, depending on the radiation level. Thus far, the material most resistant to darkening was found to be high-grade quartz (Corning 2940). It was observed to remain clear visually after days of operation. However, calibration measurements of a window removed after about three months of exposure show substantial transititance loss in the UV region. Flgure 10 shows the transmittance decreasing gently from $800 \mathrm{~nm}$ to $500 \mathrm{~nm}$, were the $105 \mathrm{~s}$ becones more pronounced. Below the shoulder at $340 \mathrm{~nm}$, the los 5 is increasingly severe with the transmittance dropping to 0.4 at $250 \mathrm{~nm}$. The surface exposed to vacuum exhibfts a lower reflectance than the surface facing air. This is attributed to surface cleaning in vacuum by beam irradiation. A careful measurement was tnitiated recently. which obtained a transmission curve for new window. It was placed near the radiation-detection cable and the radiation level was recorded for the duration of exposure. The window transmission vs wavelength was masured again. This procedure was repeated three times over a period of three months. Figure 11 compares the first and final curves. A loss of 18 is observed from $200 \mathrm{~nm}$ to about $340 \mathrm{~nm}$ beyond wich no degradation is seen. The total radiation dose was 51 krad. It is possible that the long time interval betieen runs permitted a substantial degree of recovery. Further measurements with increasing dusage will be conducted.

\section{Conclusion}

The hostile environment of ATA has adverse effects on materlals for optical diagnostics. At ATA. the chofce has been to place a minimal number of radiation-sensitive components inside the tunnel. The ioss in light collection efficiency is compensated by the ease of personnel access to equipment. Radiation tests on a ftber-optic bundle show that fluorescence is the dominant obstacle to its deployment in the accelerator victnity. Watertal darkening is the next problen, with corning 7940 guartz performing best so far.

\section{Acknowledgenent}

We thank E. Powell for providing the window transmission curves, and V. A. Farfan, G. H. Folden, $D$. Hirzel. N. D. Nielsen, P. L. Stephan for their techntcal help. Special thanks go to R. Kalibjian who was deeply involved in the optical diagnostics systen.

\section{References}

1. D. 5. Prono, IEEE Trans. Nuc1. Sc1. MS-32, 3144 (1985): A. J. Briggs, Proc. LIHAC '84 Conf. Darmstadt, West Germuny, 1984: L. Reginato, IEEE Trans. Muci. Sci, N5-30, 2970 (1983).

2. Y. P. Chong, R. Kalibjian, J. P. Cornish, J. S. Kalliman, and D. Donnelly, Bean Profile Measurements on the Advanced Test Accelerator using Optical Techniques". Proc. Beams '86 Stxth Int. Conf. High-Power Purticle Beans. Kobe, Japan, 1986. 
3. F. H. Chambers, J. S. Kallman, H. E. Slominski, Y, P. Chong. J. P. Cornish, and D. Donnelly, "Utilization of optical image data from the advanced test accelerator (ATA)", accompanying paper $787-21$ at this SPIE Conf.

4. $K$. H. Struve, Radiation Induced nolse signals in diagnostic cabling on the advanced test Accelerator". Proc, Beams 'B6 Stxth Int. Conf. High-Power Part1cle Beams, Kobe, Japan, 1986.

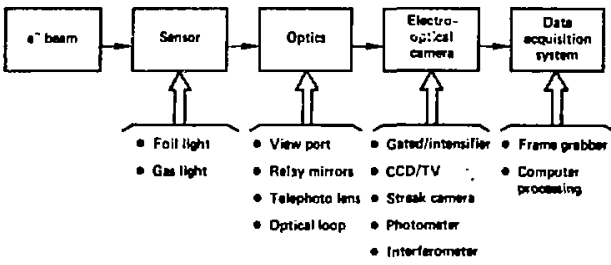

Figure 1. Schenatic of the optical diagnostic system.

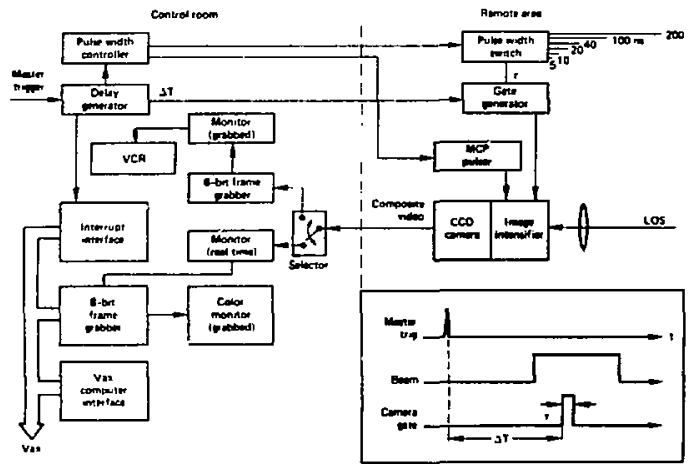

Figure 2. Circuit and timing schematic.

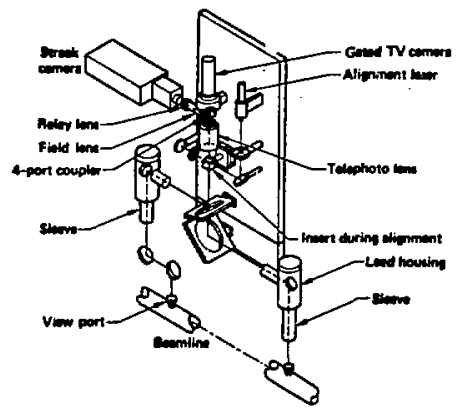

Figure 3. Optical system with dual LoS arrangement and dual detectors. 


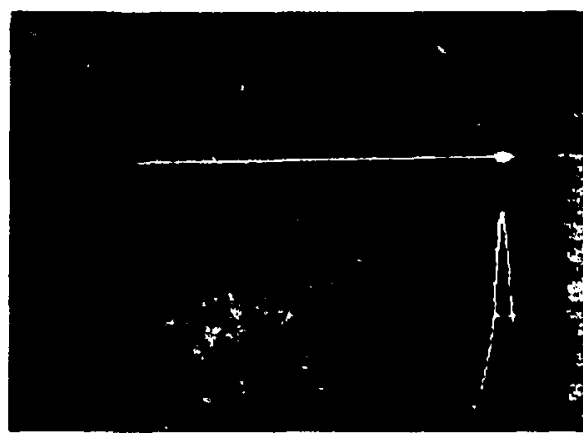

Figure 4. Example of beam-induced foll optical enfision.

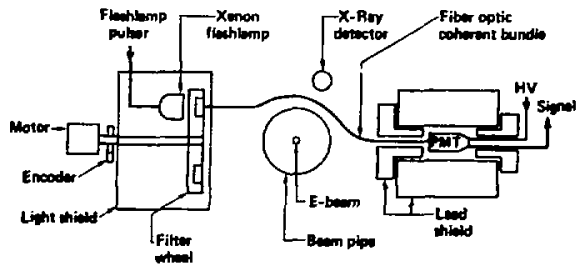

Figure 6. Experimental configuration for a fiber-optic radiation test.

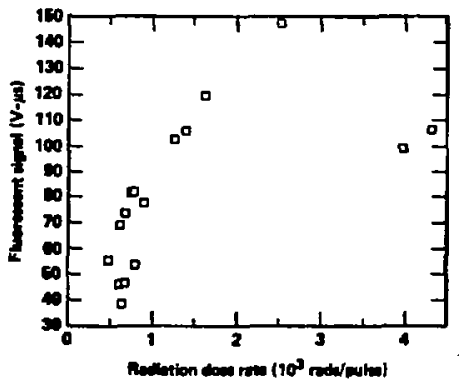

Figure 8 . Fluorescent signd vs radiation dose (rids).

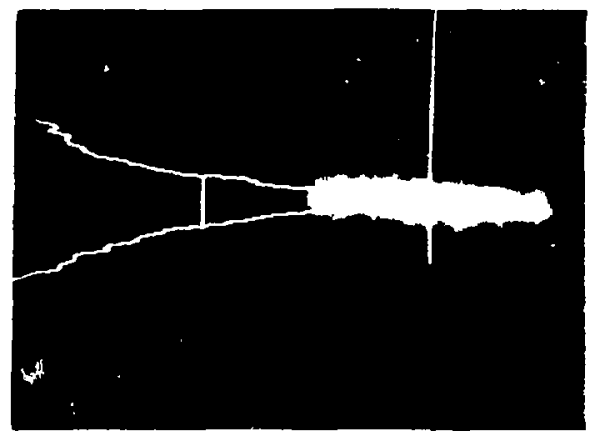

Figure 5. Example of beam-Induced gas optical enission.

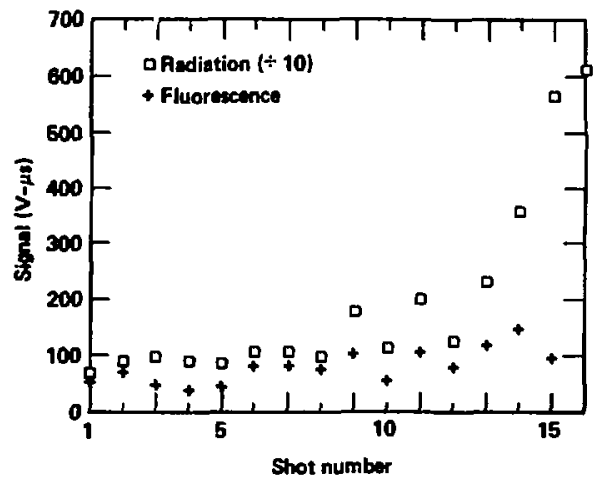

Figure 7. Time-Integrated fluorescent signal vs shot number. The bean was tuned to lose more current for the later shots.

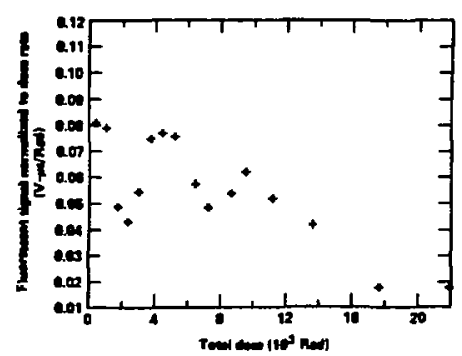

Flgure 9. Fluorescent signal normalized to dose rate plotted as a function of total dosage. 


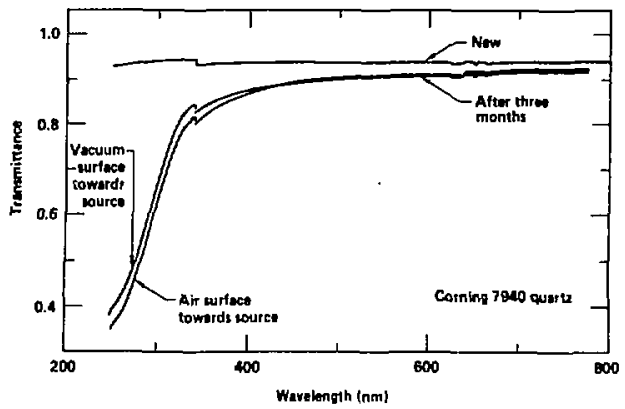

Figure 11. Long-term (three months) irradiation effect en quartz window (Corning 7940) show substantial transmittance loss in the UV region.

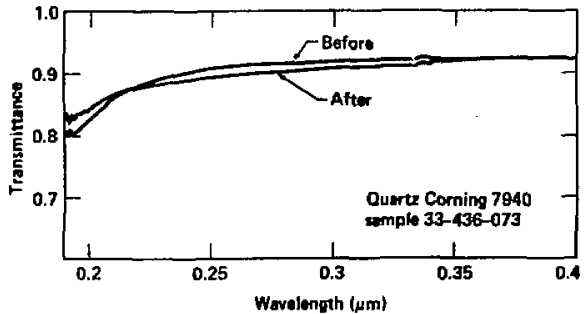

Figure 11. Transmission vs wavelength curves before and after Irradlation for high-grade quartz (Corning 7940). Radlation dose = 51 krad. 